\title{
Stress Management in Police work
}

\author{
Jayesh K. Joseph ${ }^{1}$, Dr. B. Nagarajamurthy ${ }^{2}$ \\ ${ }^{1}$ (Research Scholar, Department of Studies in Criminology \&Forensic Sciences, Maharaja's College, University \\ of Mysore, Mysore, Karnataka \& Criminologist, Kerala Police Academy, Thrissur, Kerala) \\ ${ }^{2}$ (Professor, Department of Studies in Criminology \&Forensic Sciences, Maharaja's College, University of \\ Mysore, Mysore, Karnataka)
}

\begin{abstract}
Police officers are challenged with numerous amount of emotional and physical stress. Long hours, high demands, exposure to death, and a constant threat of danger and physical harm all result in a near constant state of flight-or-fight. Overtime, this stressful state may cause serious health conditions. Unfortunately, many law enforcement officers attempt to hide their stress or downplay the physical and emotional symptoms of stress. Fear of losing trust of their fellow officers, concerns about work demotions, and belief that they will be seen as weak or unable to handle their work responsibilities forces them to remain silent about their symptoms. Untreated stress put law enforcement officers at the risk of developing numerous health problems which will impair their ability to perform their duties.
\end{abstract}

Keywords: stress, occupational stress, organizational stress, stress management, workplace stress.

\section{Overview}

Stress in organizations is a wide spread phenomenon with far-reaching practical and economic consequences. Policing is considered as one of the most stressful occupations, exposing staff to occupational, organizational, and personal stressors. Significant research findings have documented that prolonged stress has negative effects on individual health (Mohren et al., 2003; Ursin and Eriksen, 2004) as well as on employees attitude towards the organisation (Cropanzano,Rupp, and Byrne, 2003)

\section{How it occurs?}

Stress is a discrepancy between an employee's perceived state desired state, provided that the presence of this discrepancy is considered important by the employee. Thus, stress occurs when the comparison between an individual's perception and his or her desire results in discrepancy. The perception is assumed to be influenced by the physical and social environment, personal characteristics of the individual, the individual's cognitive construction of reality, and the social information. The discrepancy between the perception and desire (ie; stress) affects individual's well being and his or her coping efforts.

\section{Causative factors of stress in police work}

* Lack of sufficient strength in police stations

* Uncertainty in work schedule

* Lack of cooperation between co workers

* Lack of proper guidance and supervision by superiors

* Inequality in the work distribution

* Uncertainty in the nature of work

* Unnecessary harassments in front of the public and co workers by the superiors

* Lack of stress reduction programs at police station level

- Fixing up of accountability unequally among the staff

* Unnecessary restriction in granting leaves and permissions

- Punishments for good works done instead of appreciation

- Superiors do not have trust in their subordinate officers

* Lack of opportunity to spend time with the family members

* Unnecessary interruptions by the superiors and politicians in police work

* Nexus between the antisocial elements

* Treating police personnel as aliens instead of human beings

* Defamation by media

* Lack of protection by the department while discharging the official duties

* Lack of regular in-service training programs in recent amendments, new technologies and in newly enacted Acts

* Lack of sufficient funds and good condition vehicles in the police station 
Stressors

Stressors are conditions and events that evoke strain. Stressors can be single events such as critical life events or traumatic experiences, and they can also be chronic problems that continue over a longer period of time.

\section{Categories of stressors}

Stressors can be grouped in to the following categories;

1. Physical stressors

2. Task related job stressors

3. Role stressors

4. Social stressors

5. Work-schedule-related stressors

6. Career related stressors

7. Traumatic events

8. Stressful change processes

Physical stressors refer to aversive physical working conditions, including noise, dirt, heat, vibrations, chemical or toxic substances. They also include poor ergonomic conditions at workplace and accidents. Physical stressors have psychological effects.

Task related job stressors appear while the employee is doing a task, these stressors include high time pressure and work overload, high complexity at work, monotonous work, and disruptions.

Role stressors comprise role overload, role conflict, and role ambiguity. Role overload occurs when individuals have to do too much or too complicated work. Role conflict refers to situation with conflicting role expectations and role ambiguity refers to situations with unclear role expectations.

Social stressors express themselves in poor social interactions with direct supervisors, co-workers and others. These stressors include interpersonal conflicts at the work places, harassment, and mobbing and bullying.

Work-schedule-related stressors stem from working time arrangements. The most prominent and well researched stressors in this category are night and shift work. Additionally, long working hours and overtime belonging to this category.

Career related stressors include job insecurity and poor career opportunities.

Traumatic stressors are single events such as the exposure to disasters, major accidents, or extremely dangerous activities

Organizational change can also be regarded as a stressor. Examples include mergers, downsizing, or the implementation of new technologies.

\section{Stress reactions}

Stress in organisations affects both the individual and the organisation. Individuals can be affected at the physiological, affective, and behavioural level, and in their leisure time and family life. Stress reactions can occur immediately (short term reactions) or may take longer time to develop (long term reactions).

With respect to physiological responses, stress has an effect on cardiac system. Individuals in high strain jobs show higher blood pressure level that that of individuals in other organisations. The heart rate of the individual also increases in stressful situations. Moreover a stressful work situation is associated with increased levels of cholesterol and other metabolic and haemostatic risk factors which contribute towards the development of cardio vascular diseases.

Stress affects the excretion of hormones such as catecholamine's and cortico steroids. With increasing work demand the secretion of these hormones also increases. These physiological reactions have an effect on cardiac system. When individual experiences these physiological reactions repeatedly and over a longer period of time, may contribute to the development of illness.

The experience of stress is associated with affective reactions. In short term mood disturbances can occur. Evidence from several studies suggest that stressful work situations are associated with an increased level depressive symptoms, psycho somatic complaints and other distressed symptoms.

Stressors can also have negative effects on behavioural level. In a stressful situation attention is narrowed and working memory capacity is reduced.

\section{How to manage stress in police work? \\ $>$ Enhancement of strength in police stations \\ $>$ Internal policy reform and managerial change \\ $>$ Rescheduling the work schedule \\ $>$ Cooperation between co workers \\ $>$ Proper guidance and supervision by superiors}


$>$ Equal distribution of work among the staff

$>$ Proper defining of the nature of work

$>$ Avoid unnecessary harassments in front of the public and co workers by the superiors

$>$ Impart stress reduction programs at police station level

$>$ Fixing up of accountability equally among the staff

Granting of leaves and permission in emergency situations should be liberal

$>$ Appreciation for good works done shall not be rigid

$>$ Superiors should trust their subordinate officers

$>$ Provide opportunity to spend time with the family members

> Avoid un necessary interruptions by the superiors and politicians

$>$ Avoid nexus between the antisocial elements

$>$ Treat police personnel as human beings

$>$ Avoid defamation by media

> Protection by the department while discharging the official duties

$>$ Knowledge updation should be done regularly through in-service training programs in recent amendments, new technologies and in newly enacted Acts

$>$ Allot sufficient funds and good condition vehicles to the police station

$>$ Practice yoga and meditation

$>$ Practice Progressive muscle relaxation technique

$>$ Be spiritual

\section{Conclusion}

Several studies suggest that stress produces not only physical and mental disorders but also adversely affect the normal and effective functioning of the police department. It has been suggested that the implemented Stress Management in Law Enforcement (SMILE) program in Kerala should be given more importance so as to reduce stress in police duties meaningfully.

\section{References}

[1] Anil K.Saxena. (2003). Stress Managemnt in Police. S.V.P National Police Academy Publication, Hyderabad, 27-49

[2] Cropanzano, R., Rupp, D.E., and Byrne, Z.S. (2003). The Relationship of emotional exhausation to work attitudes, job performance, and organisational citizenship behaviors. Journal of Applied Psychology, 88(1), 160-169

[3] Mohren, D.C.L., Swaen, G.M.H., Kant, I.J., van Amelsvoort, L.G. P. M., Borm, P. J. A., and Galama, J. (2003). Common infections and the role of burnout in a dutch working population. Journal of Psychosomatic Research, 55(3), 201-208.

[4] Ursin, H., and Eriksen, H. R. (2004). The cognitive activation theory of stress. Psychoneuroendocrinology, 29(5), 567-592 